\title{
IOS Enabled Business Process Transformation: A Case Study in China
}

\author{
Luchuan $\mathrm{Liu}^{1,2}$, Wanjin $\mathrm{Hu}^{1}$ and $\mathrm{Yu}$ Chen ${ }^{1}$ \\ ${ }^{1}$ School of Information, Renmin University of China, Beijing 100872, P.R. China \\ lu_chuan@126.com wanjin@sohu.com yuchen318@gmail.com \\ ${ }^{2}$ School of Information, ShanDong University of Finance, Jinan 250014, P.R. China \\ lu chuan@126.com
}

\begin{abstract}
Taking China's two successful IOSs as study subject, this paper investigated inter-firm business process transformation enabled by IOS from four aspects, namely, integration, transfer, elimination and creation of inter-firm business processes. This study argues that IOS must be seen as the enabler of organizational structure and business process changes rather than a mere implementation tool for existing organizations and processes inside enterprises and between enterprises. Enterprises should focus on their core capability, collaborate with each other with IOS and actively achieve inter-firm business process integration and innovation.
\end{abstract}

Keywords: Inter-organizational enterprise systems, Information System integration, Inter-Enterprise collaboration, Business process transformation, case study

\section{INTRODUCTION}

One of the key applications of Information Technology is that it can transcend enterprise boundaries and be applied to inter-firm networks [1]. The information system transcending enterprise boundaries and shared by two or more enterprises is defined as Inter-Organizational Information System, IOIS, or Inter-Organizational System, IOS for short [2-3]. Generally, IOS can be divided into two categories: one is an automatic information system shared by two or more organizations [4], the other is external system integration formed by the information system of at least two organizations by means of electronic connection, for example, EDI [5]. Thus it can be seen that IOS is a definition in a broad sense, eSCM, EDI, B2B E-business, the application system like computer ticket selling through many agents all belong to this category.

This paper adopts the method of case study and lays stress on exploring how IOS enabled inter-firm business process optimization and transformation and how enterprises made corresponding changes in organizational structure, business process, etc to achieve the matching with IOS.

Please use the following format when citing this chapter:

Liu, L., Hu, W., Chen, Y., 2007, in IFIP International Federation for Information Processing, Volume 255, Research and Practical Issues of Enterprise Information Systems II Volume 2, eds. L. Xu, Tjoa A., Chaudhry S. (Boston: Springer), pp. 1497-1506. 


\section{LITERATURE REVIEW AND STUDY HYPOTHESIS}

From the definition and application of IOS, it can be seen that enterprises achieve information sharing through mutual connection and mutual intercommunication of IOS so as to reduce transaction cost, increase operating efficiency and obtain competitive advantage, which is the original purpose of enterprises for adopting IOS [6], and also scholars' focus of concern for quite a long time of period.

How enterprises use IOS to obtain competitive advantages has been a topic of study in a substantial amount of literature since the $1980 \mathrm{~s}$. To sum up, there are three ways: first, IOS can provide participants with more internal benefits; second, IOS can promote efficiency between participants; third, by introducing transfer cost, uniqueness and reducing search cost, IOS can increase participants' ability to bargain, especially initiators' [7-9].

However, the effect of IT and IOS is far greater than that. Malone et al think that IOS, when widely used in coordination of economic activities, will lead to the following three effects: first, electronic communication effect, IOS can enhance communication efficiency so information processing cost is reduced; second, electronic brokerage effect, IOS can increase the number of products to be chosen from and the quality of chosen alternative so that the process of choosing products decreases cost; third, electronic integration effect, IOS can make the connection between suppliers and customers closer [10]. The reason why electronic integration effect can make the connection between enterprises closer is that IOS adoption can optimize value chain and enhance process efficiency of the entire value chain [11] just as IT/IS adoption and absorption can enable process reengineering and reduce management hierarchy inside organizations.

Enterprises' business process transformation has always been closely related to IT. Many scholars think IT must be seen as the enabler of organization and business process changes rather than a mere implementation tool for enterprises' organizational structure and business processes. Only when IT and enterprise strategy $\&$ processes are directly integrated can process changes enabled by IT gain success [12-13]. Some former information systems such as MRPII, CAD, CAM and CRM are all the integration of local functions and processes used within one enterprise [14]. Although organizational coordination and process transformation has been taken as an important factor of organizational design and competitive strategy, for example, how to coordinate in design and manufacture department to shorten listing time of new products, the study on inter-organizational coordination, performance, process transformation, etc is relatively insufficient [15].

With the global economic integration, global supply chain and increasingly intense competition, it has become necessary to achieve inter-firm cooperation and process optimization in the concrete forms of IOS such as ERP, eSCM, eBusiness and eCommerce. With IOS enterprises can have more control over environmental uncertainty in the case of vertical disintegration, and establish stable relationship between the upstream and downstream enterprises and thus obtain benefits [12]. The best application of IOS not only lies in redesign, reengineering or rationalization of processes inside organizations, but in trans-organizational process optimization [16].

To sum up, we have the reason to put forward the following hypothesis: IOS not only promotes inter-firm information sharing, but also reduces inter-firm coordination 
cost, raises efficiency and promotes inter-firm business process transformation. Enterprises should focus on their core capability, collaborate with each other with IOS and actively achieve inter-firm business process integration and transformation which comprises the elimination, integration, transfer, creation, etc of inter-firm business processes

\section{CASE STUDY}

\subsection{Case Study Design}

The method of case study adopted by this paper is based on consideration of the following points: (1) case study is one of the methods for social science study like experiment and sample survey. Generally speaking, case study is suitable for the following situations: when "How" and "Why" questions need to be answered, when the researcher can hardly control study object, or when the focus of concern is a problem of really context [17]. The method of case study agrees with the study of this paper; (2) restricted by the degree of Chinese enterprises' IT application, in Chinese enterprises' IT application, most enterprises are coming into the stage of dataprocessing (DP) application, and only a few most advanced enterprises are beginning to establish Inter-organizational System (IOS) to offer support for successful implementation of projects like ERP [18], and such an actual situation adds to difficulty in searching for sufficient samples and carrying out the study by means of sample survey; (3) only when the research controls the process of event in an accurate, direct and systematic way can the method of experiment be adopted [17]. Obviously, for the study of this paper, actual events are not controllable.

In terms of the selection of concrete cases, relatively successful cases of IOS in China are preferred, and also the cases selected should be representative. Therefore, China Railway Computer Ticket Selling System and Shandong Sanlian Household Appliance E-business \& Modern Logistics System were selected as the study cases of this paper. The two systems both have experienced a relatively long time of test in practice, and generated good economic and social benefits.

Data collection of cases consists of the following ways: interview, recording, direct watch, participating watch, etc. In order to increase validity of the study, this paper adopted the embedded multi-case study, namely many cases are used, and meanwhile different units of analysis coexist in every case. That is, the network of the above two enterprises are selected as study object, in either network, the core enterprise of the IOS initiator is the main unit of analysis, a survey of different departments inside the core enterprise is made, and meanwhile, the representative IOS response enterprises are selected as the unit of analysis as a whole. 


\subsection{Case Descriptions}

\subsubsection{Case One}

China Railway Ticket Selling and Booking System is the state key science \& technology project of "9th Five-year Plan", initiated in 1996, and completed in 1999. The achievement won the 1999 Railway Department Scientific \& Technological Progress Awards first prize, and the National 2000 Scientific \& Technological Progress Award first prize. It was also among the nominee list as the only project of China in 2000 Computer World Smithsonian, and won the Award for final round. It is for the first time that China's application system has won the Award, and the achievement was permanently collected by Information Technology Division of National Museum of American History. China Railway Ticket Selling and Booking System can provide several tens of thousands of window machines simultaneously online selling tickets. With the annual passenger carrying capacity exceeding 1 billion people, it is the largest railway passenger ticket selling and booking system of the world, and meanwhile also known as the largest Online Transaction Processing (OLTP) System of the world. Computer ticket selling system has transcended the boundaries of railway enterprises, and based on this information system, formed interfirm networks which include many passenger ticket agencies. According to statistics, currently there are more than 4,000 railway passenger ticket agency enterprises in China.

\subsubsection{Case Two}

Shandong Sanlian Group Co., Ltd is a comprehensive economic organization with service industry as its leading industry. In 2000, Sanlian Commercial Co., Ltd under Sanlian Group became the first listed company of China's household appliance circulation industry, and since 1998 it has been successively ranked among the top 10 of China's chain industry. With the growth and expansion of household appliance chain enterprises, the relationship between household appliance manufacturers and household appliance retail chain enterprises becomes increasingly intense. It is reflected as follows: on one hand, intense conflicts sometimes occur with focus on channel control right, interest distribution, etc, and in zero sum game, the price is squeezed, but neither side gains; on the other hand, since more and more chain stores are established, and the amount of rent and operating cost is high, some chain enterprises, in the case of insufficient self-owned funds, keep their operation and expand themselves quickly by prolonging settlement date, impropriating a large amount of loans of manufacturers or charging manufacturers various high expenses, making manufacturers trapped in a vulnerable position, and the entire supply chain is likely to break at any time. By undertaking the state key science $\&$ technology project of "10th Five-year Plan"---- Household Appliance E-business \& Modern Logistics Application Demonstration Project, Shandong Sanlian integrated household appliance supply \& demand chain with E-business and modern logistics, taking the win-win road of information sharing between the upstream and downstream enterprises, quickening the response speed of order forms, reducing logistics cost of a group of enterprises, and making manufacturers, sellers and customers all gain benefits. By 
taking advantage of the E-business platform independently developed by Sanlian, CA Certification, Payment Gateway and other technical achievements, ERP system, logistics management system, POS sales system, distribution management, OMP (Order Integration Management Platform) system, B2BI system and ASP system were effectively integrated, and a comprehensive information integration and operating platform of neutralism, verticality and value adding, which ran through household appliance industry chain was established. Based on this platform, the upstream manufacturers of household appliances and the downstream distributors were integrated. So far, this system has connected 56 upstream enterprises and 128 downstream distributors.

\subsection{Case Analysis and Finding}

Based on the materials from survey, this paper used mode-matching, literal replication, cross-case cluster analysis, etc, centered on inter-firm business process transformation enabled by IOS and made analysis from the elimination, integration, transfer and creation, etc of inter-firm processes.

\subsubsection{Case One}

For the passenger ticket selling network formed by railway computer ticket selling system, stress was laid on the survey of Jinan Railway Bureau, especially Jinan Station of Jinan Railway Bureau and its outlets.

In the first half year of 1998, Jinan Railway Bureau and Shandong Sub-branch of China Construction Bank reached an agreement, through which Shandong Construction Bank became the first online ticket selling agents of Jinan Railway Bureau. Currently, Jinan Railway Bureau has more than 50 passenger ticket outlets of Construction Bank and more than 20 outlets of Hua Xia Bank in Shandong, Jiangsu, Henan, etc. Meanwhile, it also made vigorous efforts to establish cooperative relationship with more than 300 enterprises with location advantage to absorb customers, including various enterprises and organizations of hotels, restaurants, tourism, advertising, trade, communication, air transport, road transport, colleges and universities. Currently the amount of passenger ticket sales and the income of it respectively account for $25 \%$ of the total ticket sales and $30 \%$ of the passenger ticket income of the Bureau, and Director Li of Jinan Station Ticket Office called it "another sales team of railway station".

For quite a long period of time, ticket windows of stations had been the only choice for passengers who needed to buy tickets. The operation of computer ticket selling system and the passenger ticket outlet network based on it caused the following changes in passenger ticket selling process:

(1) The transfer form passenger carrier to ticket selling agency enterprise. The station, as passenger carrier, is no longer the only way to buy tickets, and ticket agency, ticket booking online, etc have become new choices. The transfer in ticket selling process made stations increase their passenger ticket sales without having more ticket selling windows. Due to convenient network and communication conditions, it is very easy to realize the transfer and extending of passenger ticket selling process For example, apart from Jian city districts such as Shizhong, Lixia, 
Tianqiao, Licheng and Huaiyin as well as surrounding city districts like Changqing and Zhangqiu, the agency enterprises of Jinan Station also cover the cities and counties of western Shandong such as Binzhou, Liaocheng, Jining and Liangshan. Many railway bureaus and stations are still cooperating with postal system, with the network covering cities and villages through postal system, carrying out postal booking $\&$ delivery business of railway passenger tickets by using ticket selling system. The passenger transport enterprises like airline and road transport which have competitive relationship with railway transport also have become members of passenger ticket agency network of railway enterprises due to their location advantage, namely distributing center of passengers.

(2) Integration of process. Based on computer ticket selling system, Jinan Railway Bureau vigorously carried out cooperation with banks, using savings network of banks and achieved inter-firm mutual benefit $\&$ mutual advantage and the integration of ticket selling and banks' savings network. Banks have the advantages of wide coverage, sufficient outlets, complete network functions, fast, clear and convenient network, and therefore without investing equipment, labor, funds and station buildings, railway enterprises can realize the extending of railway ticket selling windows, and they only need to install customer end of ticket selling software in corresponding window machines of bank outlets. This also enriches the services of banks, enhancing their competitiveness. According to manager Zhang of Jinan Railway Sub-branch of Construction Bank, savings outlets of Construction Bank also enrich the services of Construction Bank by introducing railway agency business, attracting a group of new depositors. For example, some colleges and universities choose to open an account in Construction Bank, which increases the amount of deposits and market shares of Construction Bank, and meanwhile absorbs current deposit. Under the agreement between banks and Railway Bureau, the income from passenger ticket selling agency is periodically deposited, by taking advantage of time difference, bank outlets also increase balance held on deposit. Passenger ticket selling agency also brings more agency income for bank outlets.

(3) Elimination of process. Due to the occurrence of computer ticket selling system \& agency network and the diversification of ticket selling channels, Jinan Station closed one of its two-storied ticket office located at the city center and changed it for other purpose, so we can say part of the previous ticket selling processes is eliminated.

From the above we know that railway passenger ticket selling system not only increased work efficiency, but made railway passenger transport connected with the enterprises without direct relationship with it before, causing the formation of new inter-organizational relationship, and even making opponents become cooperative partners. Based on complementary resources and abilities, different enterprises achieve the transfer, integration and intersection of business processes and thus achieve inter-firm business process innovation.

\subsubsection{Case Two}

According to statistics, currently household appliances' direct cost only accounts for $54 \%$, but circulation cost as high as $46 \%$. By developing E-business \& modern logistics and integrating household appliance supply chain, Shandong Sanlian raised 
the efficiency of supply chain as a whole, reduced logistics cost and achieved transformation of growth mode and win-win cooperation.

For the upstream suppliers, Sanlian used B2BI (Business to Business Integration), ASP (Application Service Provider), Order Integration Platform, Logistics Management System, etc to integrate the upstream resources. In September 2002, it took the lead to adopt ASP Purchase, Sales and Inventory Information Inquiry with LG Company, and meanwhile, it began to extend ASP business operation mode. After test run and practice, Sanlian updated the editions of ASP, B2BI and other systems and expanded their functions. Up to now, a total of 56 suppliers such as Hisense, TCL, Konka, LG, Simense, Kelon, Panasonic, Toshiba have used ASP Purchase, Sales and Inventory Information Inquiry System. Through inter-firm information system, the upstream and downstream enterprises can obtain information such as inventory, sales, customers and promotion in time, and achieve the functions of account settlement and product scale customization online.

In October 2002, it took the lead to undertake trial operation of B2BI-mode information system project with Hai'er Group. B2BI mode represented by Qingdao Hai'er Group achieves, when suppliers have advanced ERP system or E-business platform, the integration of manufacturer information platforms through Web Service, combining the information of the upstream and downstream enterprises of supply chain, and completely integrating information and function of information system of the upstream and downstream enterprises. After integration, the two sides achieved complete information interaction, making production and sales plan of either side implemented more efficiently. The upstream suppliers can obtain the information of Shandong market in time through the above system, share all relevant information of Sanlian household appliances' distribution channel, grasp the status of inventory and sales of the entire channel, spread no-time delay promotion information, and have customer information of chain channel as well as demand information of products. And meanwhile, the following changes occurred to inter-firm processes:

(1) Creation of processes. Sanlian's integrating the upstream and downstream resources with information system is a process of inter-firm mutual benefit and cooperation, and also a process of optimization and integration for the inside of an enterprise and the entire supply chain. According to the introduction by Ms. Gao Jinling of Sanlian Logistics, Sanlian changed the chain distribution department within its system into a professional logistics supplier providing $3 \mathrm{C}$ services. That is, a third party of logistics supplier which mainly provides computer, communication and consumer electronics. Sanlian Logistics is a specialized logistics service supplier for 3C products of Sanlian Commercial Co., Ltd. With 20 years of experience accumulation, it has developed a set of advanced service system providing regional logistics for $3 \mathrm{C}$ products, with its service network covering Shandong Province and also extending to county-level market. Especially, it has established strategic cooperative relationship with more than 300 upstream suppliers and more than 200 downstream chain stores, with rich experience in operating skills, logistics service awareness of a third party, etc. Now, Sanlian Logistics can provide all-round services such as stock, transport, loading \& unloading, commercial inspection, reverse logistics, information and insurance, and it has become one of the best in this field. On July 7, 2006, it was ranked among the Top 50 Enterprises of 2005 Shandong Logistics and Purchase Industry in overall strength. Sanlian's strategic objective of 
logistics is to become the largest logistics distributor of the household appliance field by integrating resources. And they set the objectives for newly-established logistics base as follows: during phase 1, it is established into a professional household appliance logistics base, with its sales market covering Shandong Province, undertaking agency business and buying the right of exclusive agency of household appliance brands, becoming the only channel for outside household appliance brands to enter Shandong; during phase 2, it is established into Shandong logistics base, undertaking logistic agency business in an all-round way.

(2) Transfer of processes. The upstream manufacturers of household appliances use the E-business \& logistics platform provided by Sanlian and greatly facilitate the management of production, supply and sales, making the management of supply chain visible, and the previously processes outside enterprises has now become important links of production and management inside enterprises. In an interview, Gao Jinling, General Manager of Sanlian Logistics Company told a story: in order to see how much effect E-business platform has on factories, one day, Sanlian closed the platform on purpose. It turned out that one after another factories called to ask what the matter was. A household appliance enterprise from the South even said, "do open it please, or we really don't know how to work".

(3) Integration and elimination of processes. In September 2002, Sanlian and Xiahua Electronics started their strategic cooperation, and together the two sides tried running a new supply chain system of household appliance production and circulation. According to the agreement, Xiahua Electronics removed the storehouses in Jinan, Weifang, Yantai and other places. Sanlian Logistics began to provide Xiahua Electronics with the services of stock, transport, etc in Shandong, and meanwhile Xiahua joined Sanlian's data platform, achieving the integration of information system, and Xiahua's sales network in Shandong was brought into Sanlian's system. In the past, factories' products would have to be put in their storehouses of all places step by step before they reached sellers, but now the new system removed this link, making inter-firm processes less complicated, and also reducing logistics cost. Thus, Xiahua Electronics focus its core capacity on the development and production of new products, and based on complementary resources and abilities, different enterprises form closely cooperative partnership relationship. Thanks to this, when Xiahua's amount of sales was increased by $30 \%$, its stock was decreased by $70 \%$, the number of days of goods turnover was reduced from 46 days to 11 days, stock expenses were reduced by $45 \%$, loading \& unloading expenses by $30 \%$, and office expenses by $83 \%$.

It is clear that Sanlian not only took information system as a technical tool to enhance efficiency inside enterprises and between enterprises, but integrated household appliance supply chain with it, promoting organization and process changes inside enterprises and between enterprises.

\subsection{Cross-case Cluster Analysis}

Mode-matching and literal replication were adopted to prove hypothesis above, and the following is from the aspects such as elimination, integration, transfer, creation and performance of inter-firm process, by clustering case facts, working out 
mapping tables of case materials (omitted for lack of space). Comprehensive application of the case analysis methods above helped us to draw study conclusions.

\section{CONCLUSION AND FURTHER TASKS}

Combining the above cases, this paper laid stress on exploring how IOS enabled inter-firm business process optimization and transformation. The study shows that IOS makes inter-firm process innovation become a possibility and a certainty. The enterprises in the cases, when implementing IOS, paid attention to making organizations inside enterprises \& between enterprises match with process changes, so they could not only promote information sharing between enterprises, reducing inter-firm coordination cost and enhancing efficiency, but also promote the integration, transfer, creation, etc of inter-firm processes. Enterprises should focus on their core capability, collaborate with each other with IOS and actively achieve interfirm business process integration and innovation. This study further shows that IOS must be seen as the enabler of organizational structure and business process changes rather than a mere implementation tool for existing organizations and processes inside enterprises and between enterprises.

China has emphasized repeatedly that we should reform traditional industries with IT application, to focus on E-business application in backbone enterprises, realize the integration of inter-firm business processes of different enterprises and establish connected information system network, with industry chain as a foundation and supply chain management as a key point. So the study of inter-firm business process transformation enabled by IOS is of great practical significance, and it plays an active role and can be used for reference when enterprises adopt inter-organization information system.

Further study can be carried out in the following aspects, first, to further enlarge the number of cases to increase credibility and external validity of the study; secondly, to further detail measurement of four dimensionality of inter-firm business process transformation enabled by IOS, and carry out demonstration study on a larger scale by way of questionnaire.

\section{REFERENCES}

1. F.W. McFarian and J.L. McKenney, The Information Archipelago - Governing the New World, Harvard Business Review. Volume 61, Number 4, pp.91-99, (1983).

2. S. Barrett and B. Konsynski, Interorganization Information Sharing System, MIS Quarterly. Volume 6, Special issues, pp.93-104, (1982).

3. J.I. Cash and B.R. Konsynski, IS Redraws Competitive Boundaries, Harvard Business Review. Volume 63, Number 2, pp.134-142, (1985).

4. J.I. Cash, Interorganizational Systems: An Information Society Opportunity or Threat?, The Information Society. Volume 3, Number 3, pp.199-228, (1985).

5. P.M.C. Swatman, and P.A. Swatman, EDI System Integration: A Definition and Literature Survery, The Information Society. Volume 8, Number 2, pp.169-205, (1992). 
6. N. Reekers and S. Smithson, EDI in Germany and the UK: strategic and operational use, European Journal of Information Systems. Volume 3, Number 3, pp.169-178, (1994).

7. M.E. Poter and V.E. Millar, How information gives you competitive advantage, Harvard Business Review. Volume 63, Number 4, pp.149-160, (1985).

8. B.R. Konsynski and E.W. McFarian, Information Partnership-Shared Data, Shared scale, Havard Business Review. pp.114-120, (1990).

9. T. Jelassi and O. Figon, Competing through EDI at Brun Passport: Achievements in France and ambitions for the single European market, MIS Quarterly. Volume 18, Number 4, pp.337-352, (1994).

10. T.C. Powell and A. Dent-Micallef, IT as Competitive Advantage: The Role of Human, Business, and Technoledge Resources, Strategy Management Journal. Volume 18, Number 5, pp.375-405, (1997).

11. T.W. Malone, J. Yates, and R.L. Benjamin, Electronic markets and electronic hierarchies, Communication of the ACM. Volume 30, Number 6, pp.484-497, (1987).

12. T.H. Davenport, Process Innovation: Reengineering Work Through Information Technology (Harvard Business School Press: Boston, MA, 1993)

13. A. Serrano and M.D. Hengst, Modelling the integration of BP and IT using business process simulation, Joumal of Enterprise Information Management. Volume 18, Number $5,(2005)$.

14. L.D. Xu, Editiorial: Inaugural issue, Enterprise Information System. Volume 1, Number 1, pp.1-2, (2007).

15. T.H. Clark and H.G. Lee, Performance, interdependence and coordination in business-tobusiness electronic commerce and supply chain management, Information Technology and Management. Volume 1, Number 1, pp.85-105, (2000).

16. H.H. Teo and K.K. Wei, Predicting intention to adopt interorganizational linkages: An institutional perspective, MIS Quarterly. Volume 27, Number 1, pp.19-49, (2003).

17. R.K. Yin, Case study design and method(ChongQing University Press: ChongQing, 2004)

18. F.W. McFarian, G. Chen, and K. Reimers, Digital China Holdings Limited: ERP as a Platform for Building New Capabilities, Harvard Business School Case Study, Number 9302-080 (Harvard Business School Publishing: Boston, May 21, 2002) 